\title{
Restaurações indiretas em resina composta em cavidades com diferentes profundidades: Relato de caso
}

\author{
Indirect restorations in composite resin in cavities with different depths: Case report \\ Restauraciones indirectas en resina compuesta en cavidades de diferentes profundidades: Reporte
}

de caso

Recebido: 30/04/2021 | Revisado: 09/04/2021 | Aceito: 12/04/2021 | Publicado: 24/04/2021

\author{
Juliana Lisboa Feitoza Lira \\ ORCID: https://orcid.org/0000-0001-7237-1351 \\ Centro Universitário Brasileiro, Brasil \\ E-mail: jujulisboa21@gmail.com \\ Lidiane Lins Dutra \\ ORCID: https://orcid.org/0000-0001-9260-0211 \\ Centro Universitário Brasileiro, Brasil \\ E-mail: lidianelins91@gmail.com \\ Valéria Cristina Rodrigues da Costa \\ ORCID: https://orcid.org/0000-0003-1227-7341 \\ Centro Universitário Brasileiro, Brasil \\ E-mail: valeriarodrigues2010@yahoo.com.br \\ Maria Emanuella Letícia da Silva \\ ORCID: https://orcid.org/0000-0002-7159-1165 \\ Centro Universitário Brasileiro, Brasil \\ E-mail: emanuelaleticia@hotmail.com \\ Natália Gomes de Oliveira \\ ORCID: https://orcid.org/0000-0001-6937-1537 \\ Centro Universitário Brasileiro, Brasil \\ E-mail: nataliagomes04@hotmail.com \\ Luís Felipe Espíndola-Castro \\ ORCID: https://orcid.org/0000-0002-1923-8057 \\ Centro Universitário Brasileiro, Brasil \\ E-mail: lipe_espindola@hotmail.com
}

\begin{abstract}
Resumo
Restaurações indiretas em resina composta são comumente usadas em dentes posteriores nas diferentes cavidades, permitindo maior resistência ao desgaste, adaptação marginal, estabelecimento de contatos proximais e maior dureza, uma vez que passam pelo processo de termopolimerização. O objetivo desse estudo é relatar um caso clínico de substituição de restaurações em amálgama por restaurações indiretas em resina composta em cavidades com diferentes profundidades. Paciente, sexo feminino, 34 anos, procurou a clínica odontológica de uma instituição privada, queixando-se de insatisfação estética nas restaurações em amálgama nos dentes 45, 46 e 47. Após exame clínico, devido à extensão das cavidades, foi sugerido a realização de restaurações indiretas em resina composta nos três elementos. Após a remoção do amalgama, com ponta diamantada, avaliou-se as profundidades das cavidades dos dentes. No dente 45 , realizou-se tratamento endodôntico e instalação de pino de fibra de vidro. No dente 46 foi realizado um capeamento pulpar indireto e no dente 47 não foi realizado nenhum tratamento de proteção pulpar. Posteriormente, os dentes foram preparados para restaurações indiretas com ponta diamantada \#3131, em seguida, foram moldados com silicone de adição, prosseguindo com vazamento do molde com gesso tipo IV. O modelo foi troquelizado pela técnica de duplo vazamento e as restaurações em resina composta foram confeccionadas sobre o modelo. Na sessão seguinte, as restaurações foram cimentadas com cimento resinoso dual autoadesivo. Por fim, foi realizado o ajuste oclusal, seguido do acabamento e polimento. As terapêuticas empregadas foram eficazes para recuperar a forma anatômica e estética dos elementos dentários envolvidos.
\end{abstract}

Palavras-chave: Estética dental; Reabilitação bucal; Resinas compostas.

\begin{abstract}
Indirect composite resin restorations are commonly used on posterior teeth in different cavities, allowing greater wear resistance, marginal adaptation, establishment of proximal contacts and greater hardness, since it undergoes the process of thermopolymerization. The aim of this study is to report a clinical case of replacing amalgam restorations by indirect restorations in composite resin in cavities with different depths. Female patient, 34 years old, went to the dental clinic of a private institution, complaining of aesthetic dissatisfaction in amalgam restorations on teeth 45,46 and 47 . After
\end{abstract}


clinical examination, due to the extension of the cavities, it was suggested to perform indirect restorations in composite resin in the three elements. After removing the amalgam, with a diamond tip, the depths of the tooth cavities were evaluated. In tooth 45, an endodontic treatment and installation of a fiberglass pin were performed. In tooth 46, an indirect pulp capping was performed and in tooth 47 , no pulp treatment was performed. Subsequently, the teeth were prepared for indirect restorations with diamond tip \# 3131, then they were molded with addition silicone, proceeding with casting of the mold, with type IV plaster. The model was die-cut using the double casting technique and the composite resin restorations were made on the model. In the following session, the restorations were cemented with dual self-adhesive resin cement. Finally, occlusal adjustment was performed, followed by finishing and polishing. The therapies employed were effective in recovering the anatomical and aesthetic shape of the dental elements involved.

Keywords: Dental aesthetics; Oral rehabilitation; Composite resins.

\section{Resumen}

Las restauraciones indirectas de resina compuesta se utilizan comúnmente en dientes posteriores en diferentes cavidades, permitiendo mayor resistencia al desgaste, adaptación marginal, establecimiento de contactos proximales y mayor dureza, ya que sufre el proceso de termopolimerización. El objetivo de este estudio es reportar un caso clínico de sustitución de restauraciones de amalgama por restauraciones indirectas en resina compuesta en cavidades con diferentes profundidades. Paciente de sexo femenino, 34 años, acudió a la clínica odontológica de una institución privada, quejándose de insatisfacción estética en las restauraciones de amalgama en los dientes 45, 46 y 47 . Tras el examen clínico, debido a la extensión de las caries, se sugirió realizar restauraciones indirectas en resina compuesta en los tres elementos. Después de retirar la amalgama, con una punta de diamante, se evaluó la profundidad de las caries dentales. En el diente 45 se realizó un tratamiento de endodoncia e instalación de un pin de fibra de vidrio. En el diente 46 se realizó un recubrimiento pulpar indirecto y en el 47 no se realizó tratamiento pulpar. Posteriormente, se prepararon los dientes para restauraciones indirectas con punta de diamante \# 3131, luego se moldearon con silicona de adición, procediendo al vaciado del molde, con yeso tipo IV. El modelo se fundió a presión mediante la técnica de doble colada y las restauraciones de resina compuesta se realizaron sobre el modelo. En la siguiente sesión, las restauraciones se cementaron con cemento de resina dual autoadhesivo. Finalmente, se realizó el ajuste oclusal, seguido del acabado y pulido. Las terapias empleadas fueron efectivas para recuperar la forma anatómica y estética de los elementos dentales involucrados.

Palabras clave: Estética dental; Rehabilitación oral; Resinas compuestas.

\section{Introdução}

Dentes com extensa destruição coronária podem estar associados a diferentes condições clínicas como fraturas, processos cariosos ou pelo acesso do tratamento endodôntico. O restabelecimento da anatomia adequada e a recuperação mecânica destes dentes lesionados torna-se um grande desafio para o cirurgião-dentista. Nesses casos, o remanescente dentário fragilizado requer resoluções restauradoras mais complexas (Pessoa et al., 2019; Stape et al., 2013). Dentre as terapêuticas disponíveis, a resina composta é um dos materiais mais utilizados em dentes posteriores que apresentam boas propriedades mecânicas, estéticas e funcionais (Cardoso et al., 2012).

Essa classe de materiais possibilita a realização de procedimentos mais conservadores e possui considerável durabilidade (Angeletaki et al., 2016; Espíndola-Castro et al., 2019). Entretanto, em cavidades extensas, o emprego da técnica direta em resina composta pode não ser efetivo para resistir as cargas mastigatórias (Monteiro et al., 2017). A contração de polimerização é outro fator indesejado nessa técnica, que pode favorecer formação de trincas, infiltrações, pigmentações da margem e sensibilidade pós-operatória. Esses fatores são reduzidos na técnica indireta, uma vez que a contração de polimerização ocorre no modelo de gesso sendo compensada durante a cimentação (Cardoso et al., 2012; Monteiro et al., 2017; Hansrani; Laverty \& Brunton, 2019).

O emprego do procedimento restaurador indireto com resina composta em dentes posteriores vem sendo a principal alternativa clínica para minimizar esses inconvenientes neste tipo de cavidade (Dias et al, 2017; Huth et al., 2011). Na técnica indireta, as restaurações são confeccionadas fora da boca, onde passam por uma termopolimerização adicional em temperaturas elevadas, gerando um tratamento térmico "homogeneizador" da matriz de resina, aumentando expressivamente os valores de microdureza do material o que resulta em maior resistência (Guimarães et al., 2020; Dias et al., 2017). A técnica permite a obtenção de melhor adaptação marginal e contatos proximais que facilita a confecção da anatomia oclusal quando comparado 
ao método restaurador direto (Azeem \& Sureshbabu, 2018).

Restaurações indiretas inlay e onlay confeccionadas em cerâmica, vem entrando em desuso na prática clínica devido ao seu potencial de fratura (Ramírez et al., 2016). As cerâmicas não dissipam os esforços mastigatórios, apenas os transmite para o remanescente dentário que se encontra fragilizado (Martins et al., 2010; Mori et al., 1997). Nesse contexto, as resinas compostas são excelentes alternativas para o emprego da técnica indireta, pois, possuem módulo de elasticidade similar à dentina além de apresentar capacidade em se deformar durante a dinâmica mastigatória e absorver tais impactos (Cardoso et al., 2012).

Além da extensão da cavidade e decisão sobre a técnica empregada, o profissional deve avaliar também a profundidade da cavidade e a integridade do tecido pulpar. Injúrias pulpares irreversíveis podem ser causadas por ação dos materiais odontológicos restauradores utilizados (Poimenova et al., 2018). A capacidade dos monômeros residuais em provocar reações tóxicas no tecido pulpar está diretamente relacionada à permeabilidade e umidade da dentina (Costa et al., 2018). Próximo à câmara pulpar, o diâmetro e o número de túbulos dentinários por área aumentam, resultando em alta permeabilidade (Costa $e t$ al., 2014).

Assim, antes de realizar o procedimento restaurador propriamente dito, o profissional deve realizar dependendo da profundidade, a proteção do complexo pulpar, com o objetivo de preservar sua vitalidade (Casarin et al., 2016). Em outros casos, quando o dente já é tratado endodonticamente e exibe grandes destruições na região da coroa podem ser indicados os pinos intrarradiculares, para reforçar a adesão da restauração ao remanescente dental (Melo et al., 2015).

Desse modo, o objetivo do presente estudo é relatar um caso clínico de restaurações em resina composta confeccionadas pela técnica indireta em cavidades com diferentes profundidades.

\section{Relato de Caso}

Paciente do sexo feminino, 34 anos de idade, procurou atendimento no curso de graduação em Odontologia da UNIBRA, queixando-se de insatisfação estética nas restaurações em amálgama de prata nos elementos 45, 46 e 47 (Figura 1).

Figura 1. Aspecto clínico inicial.

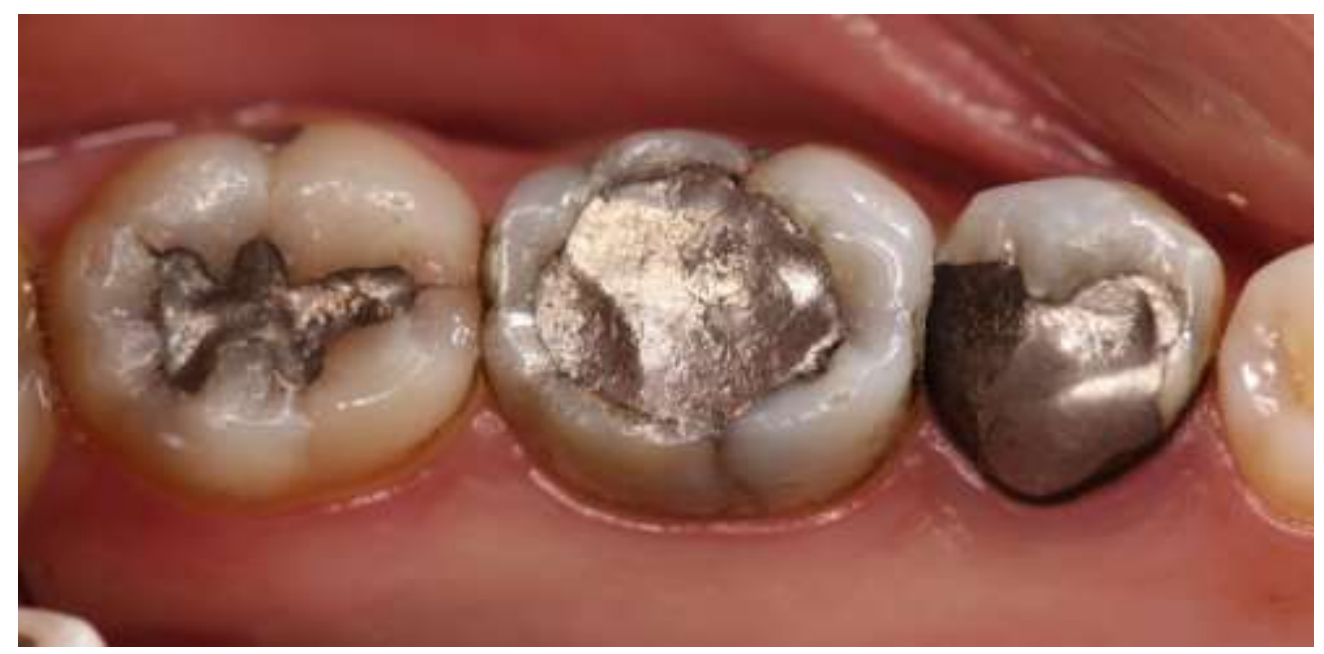

Fonte: Autores.

Após exame clínico, devido à extensão das cavidades, foi sugerida a realização de restaurações indiretas em resina composta nos três elementos. Com a autorização da realização do planejamento proposto, o tratamento procedeu em etapas. O presente estudo relata um caso clínico que teve a publicação autorizada pelo paciente por meio da assinatura do termo de consentimento livre e esclarecido (TCLE). 


\section{Etapa 1: Remoção das restaurações insatisfatórias.}

Inicialmente, foram removidas todas as restaurações preexistentes insatisfatórias, com a utilização de ponta diamantada cônica dupla (carretel) \#1045 (KG Sorensen, São Paulo, Brasil) (Figura 2).

Figura 2. Remoção das restaurações metálicas.

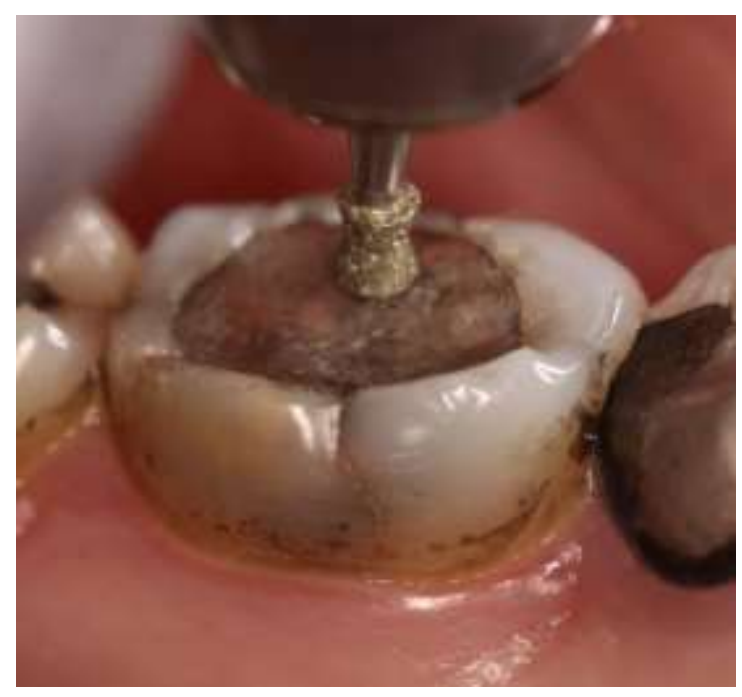

Fonte: Autores.

Após a remoção dos materiais restauradores, pôde-se constatar o grau de complexidade de cada cavidade. No dente 47, havia a presença de uma cavidade média e, portanto, não foi realizado nenhum tratamento de proteção pulpar. No dente 46, havia uma cavidade muito profunda, mas sem exposição pulpar e o dente 45 apresentava comunicação com a cavidade pulpar e pouca estrutura dentária (Figura 3).

Figura 3. Aspecto clínico após a remoção das restaurações em amálgama de prata.

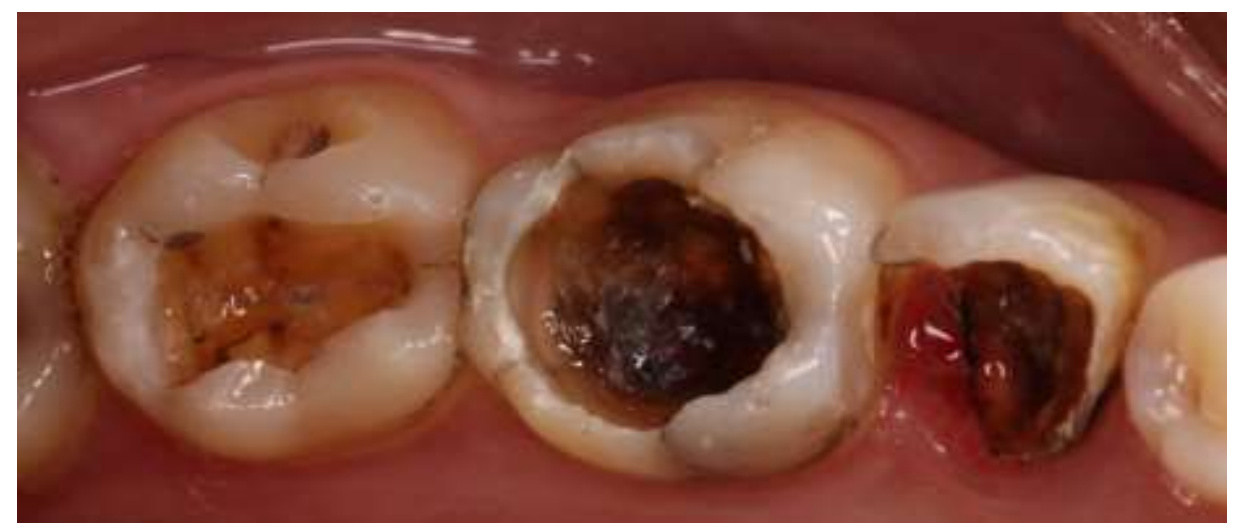

Fonte: Autores.

Nesse contexto, o tratamento para cada elemento foi diferente, devido a profundidade da cavidade e grau de complexidade. Após a remoção das restaurações, o tratamento seguiu com a etapa seguinte. 


\section{Etapa 2: Proteção do complexo dentino-pulpar do dente 46.}

Foi realizado o isolamento absoluto do campo operatório e a profilaxia, com pasta de pedra pomes, água e escova de Robinson. Na sequência, foi aplicado o cimento de hidróxido de cálcio (Liner, Coltene, Altstätten, Suíça) na parede pulpar, seguido da aplicação de cimento de ionômero de vidro fotopolimerizável (Riva Light Cure, SDI, Victória, Australia), com auxílio da seringa aplicadora (Precision, Maquira, Paraná, Brasil) (Figura 4).

Figura 4. Capeamento pulpar indireto. (A) Aspecto clínico inicial. (B) profilaxia com pedra pomes. (C) Aspecto clínico após profilaxia. (D) Aplicação de cimento de hidróxido de cálcio. (E) Aplicação de cimento de ionômero de vidro.

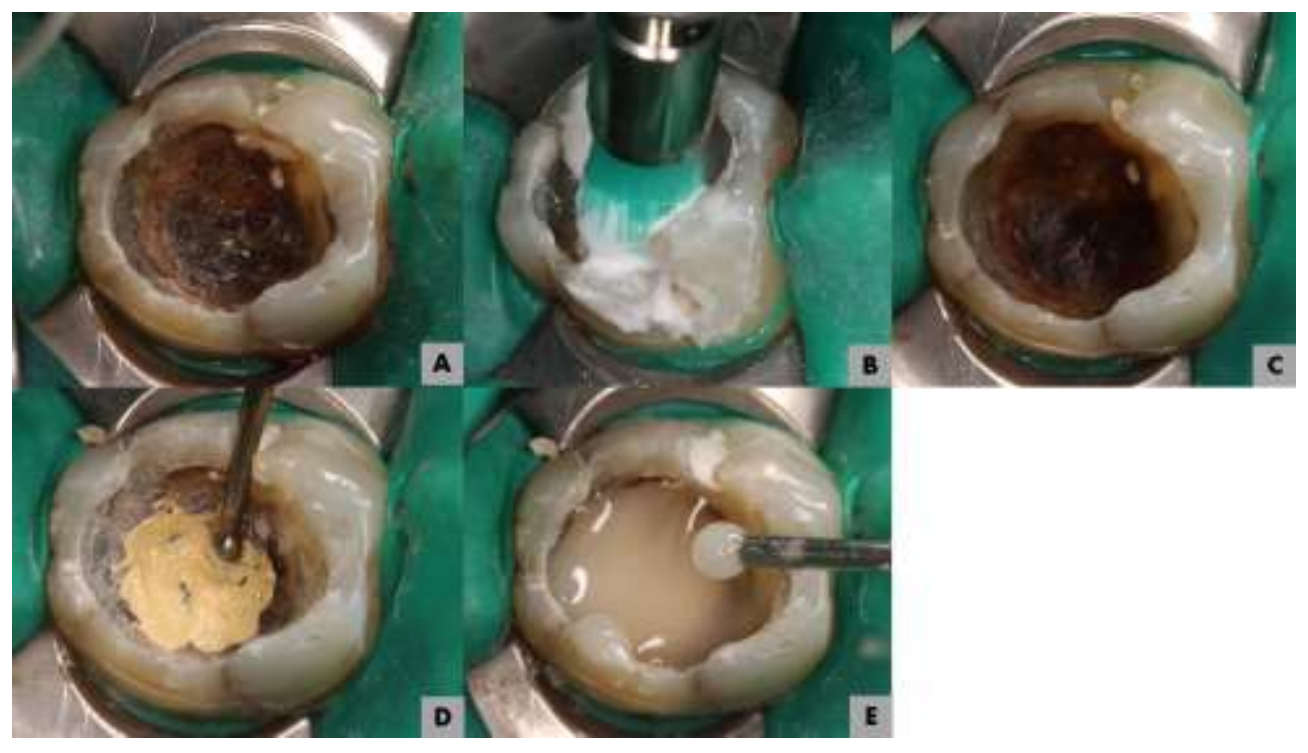

Fonte: Autores.

Após essa etapa, todos os dentes foram restaurados provisoriamente e a paciente foi encaminhada para a realização do tratamento endodôntico do dente 45. Após a finalização do tratamento endodôntico, o tratamento prosseguiu com a etapa 3.

\section{Etapa 3: Instalação de pino de fibra de vidro no dente 45.}

Após tratamento endodôntico no dente 45, foi realizada uma cirurgia para aumento de coroa clínica e, após o período cicatricial (dois meses), foi instalado o pino de fibra de vidro. Foi realizado o isolamento absoluto do campo operatório (Dental Dam, Coltene, Altstätten, Suíça), seguido da desobturação do canal preservando 4mm de material obturador apical com brocas gattes, largo e a própria broca modeladora de canal do pino de fibra de vidro (Whitepost DC, FGM, Santa Catarina Brasil). Em seguida, foi realizada a prova do pino e marcação do corte com caneta marcadora de CD (metade da coroa clínica), corte com ponta diamantada cilíndrica e nova prova do pino no interior do canal (Figura 5). 
Figura 5. Etapas prévias para instalação do pino de fibra de vidro. (A) Remoção da restauração provisória e isolamento absoluto. (B) Desobturação do canal. (C) Prova e marcação do pino. (D) Corte do pino com ponta diamantada. (E) Prova final do pino de fibra de vidro.

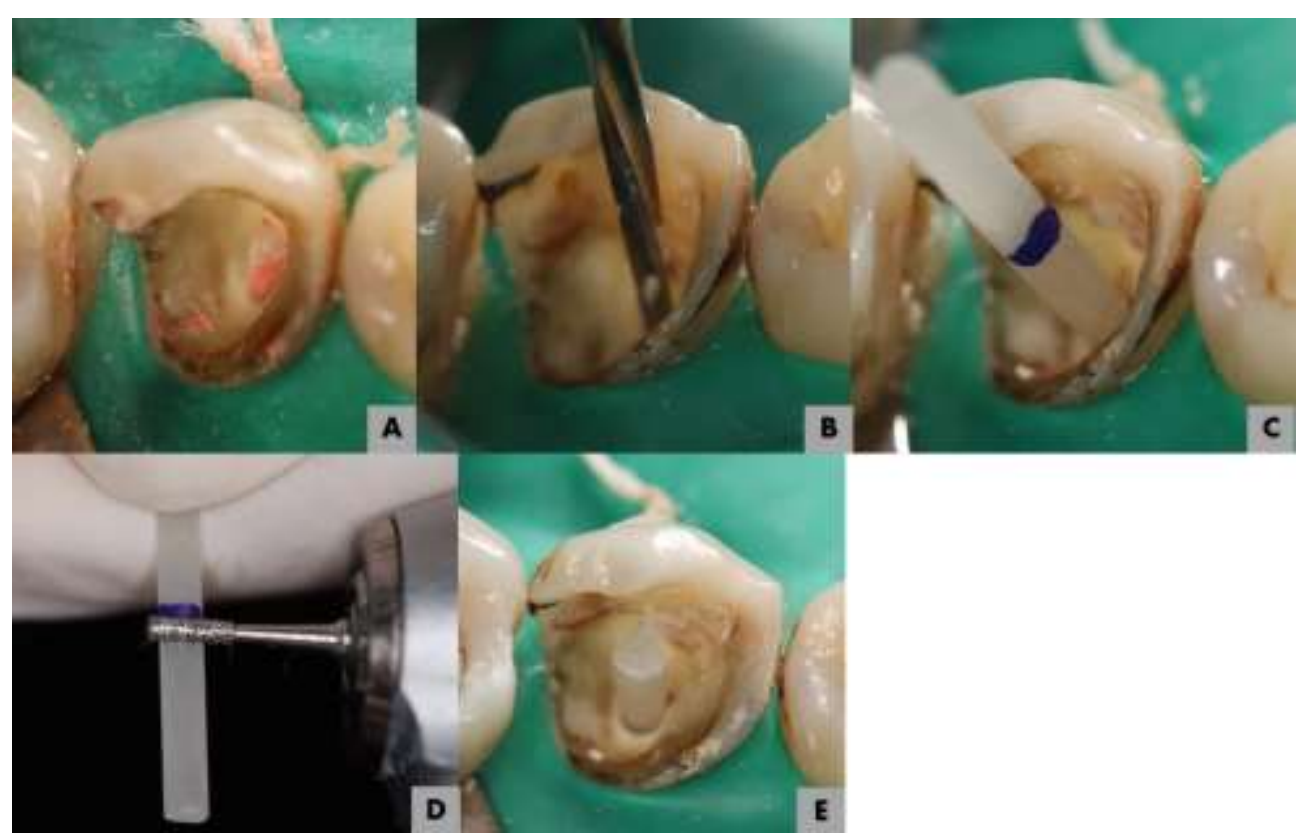

Fonte: Autores.

Na sequência, foi realizada profilaxia com pasta de pedra pomes e água, seguido de condicionamento com ácido fosfórico a 37\% (Magic Acid, Coltene, Altstätten, Suíça), por 30 segundos no esmalte e 15 segundos na dentina, e completa remoção com spray de água/ar. O conduto foi seco com cones de papel absorvente. O pino foi tratado com ácido fosfórico a $37 \%$ por 1 minuto, e seguiu-se com a aplicação do silano (Prosil, FGM, Santa Catarina, Brasil). Após a evaporação do silano, o pino recebeu uma fina camada de adesivo universal (Single Bond Universal, 3M-ESPE, Minnesota, EUA). O pino foi cimentado com cimento resinoso dual autoadesivo (U200, 3M-ESPE, Minnesota, EUA) com inserção única do pino no interior do canal radigular. Por fim, a cavidade foi preenchida com resina composta nanoparticulada (Z350, 3M-ESPE, Minnesota, EUA) (Figura 06). 
Figura 6. Cimentação do pino de fibra de vidro. (A) Condicionamento com ácido fosfórico no remanescente dental. (B) Secagem do conduto com cone de papel absorvente. (C) Condicionamento do pino com ácido fosfórico. (D) Aplicação do silano. (E) Cimentação do pino com cimento resinoso dual. (F) Preenchimento da cavidade com resina composta nanoparticulada.

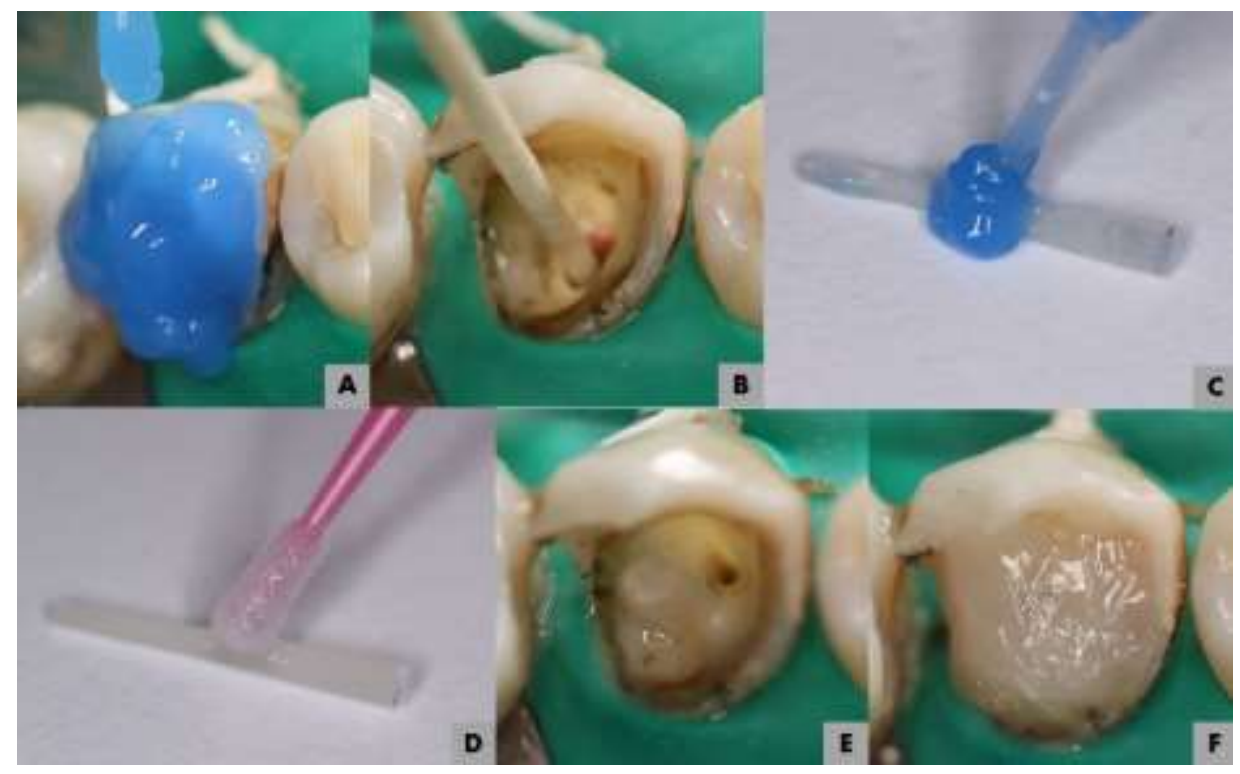

Fonte: Autores.

Após a cimentação do pino, o tratamento seguiu para a etapa 4.

\section{Etapa 4: Preparo para restauração indireta em resina composta nos dentes 45, 46 e 47.}

Para o preparo da restauração indireta foi utilizada uma ponta diamantada \#3131 (KG Sorensen, São Paulo, Brasil). A ponta foi deslizada por todos os dentes no sentido do longo eixo. Deste modo, foi possível a conformação de preparos cavitários ideais para restaurações indiretas com paredes circundantes divergentes para oclusal, parede pulpar plana, ângulos internos arredondados e ângulo cavo superficial nítido e sem bisel (Figura 7).

Figura 7: Preparos cavitários para restaurações indiretas em resina composta.

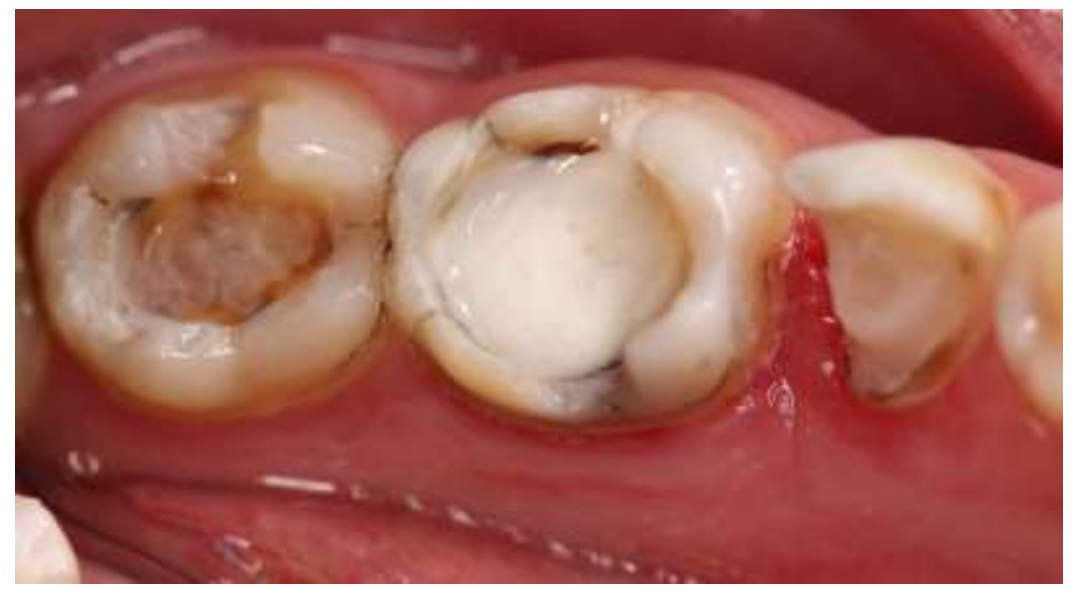

Fonte: Autores.

Após a finalização dos preparos, os dentes foram moldados com silicone de adição pela técnica de dupla impressão (President, Coltene, Altstätten, Suíça) (Figura 8). 
Figura 8. Moldagem dos preparos cavitários com silicone de adição.

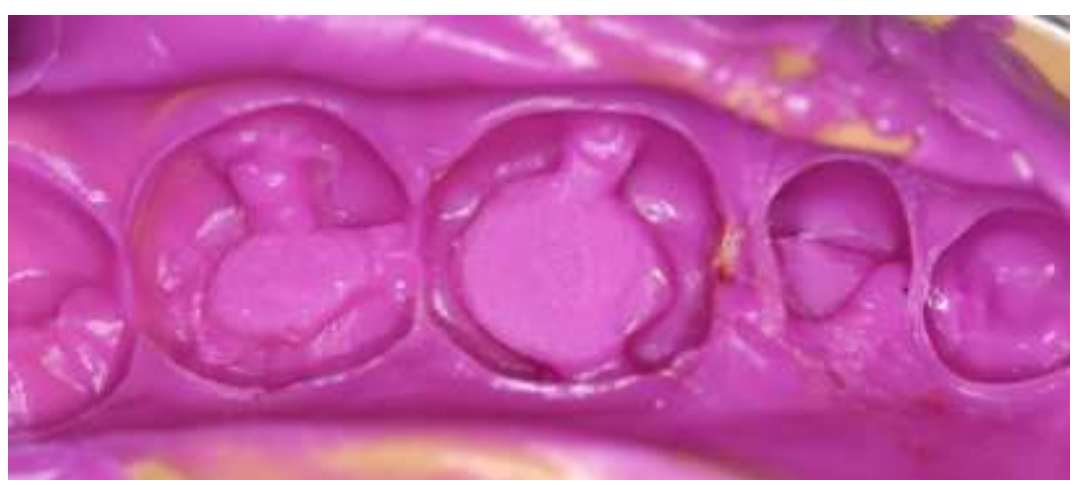

Fonte: Autores.

Após essa etapa, foi inserido material restaurador provisório nas cavidades (Applic, Maquira, Paraná, Brasil) e prosseguiu-se com os procedimentos laboratoriais na etapa 05.

\section{Etapa 05: Troquelização do modelo de gesso e escultura das restaurações.}

O silicone de adição foi vazado 2 horas após moldagem, com gesso especial tipo IV (Dentsply, Pensilvânia, EUA). Em seguida, no dente 45, que havia envolvimento com a região interproximal, foi realizado o corte do gesso com disco diamantado e modelagem do gesso, com broca minicut. O objetivo desta etapa foi individualizar o dente a ser restaurado de modo que sua base ficasse expulsiva, para confecção da troquelização. Nos demais dentes (46 e 47), como não havia envolvimento com a interproximal e não havia necessidade de remoção destes dentes do modelo para escultura, não foi realizado acabamento refinado e expulsivo destes dentes (Figura 9).

Figura 9. Troquelização do modelo de gesso. (A) Vazamento da moldagem com gesso tipo IV. (B) Separação do dente 45 com disco diamantado. (C) Desgaste expulsivo do modelo para troquelização. (D) Troquéis individualizados.

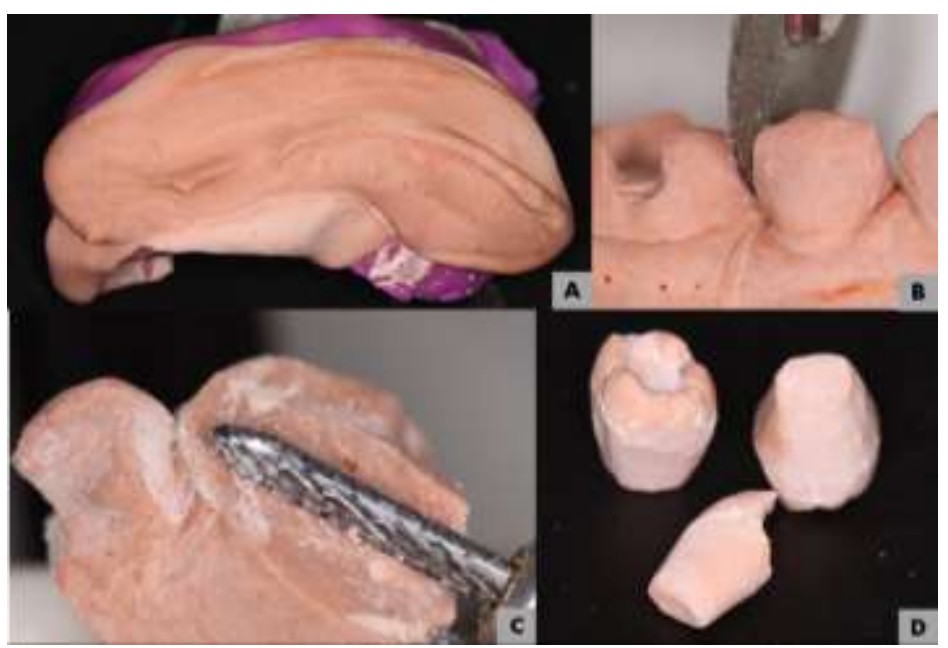

Fonte: Autores.

Em seguida, os troquéis foram reposicionados na moldagem e o modelo do dente 45 foi lubrificado com lubrificante hidrossolúvel (KY, Jhonson \& Jhonson, Nova Jersey, EUA). Posteriormente, a moldagem foi novamente vazada e foi confeccionado um orifício na base do troquel do dente 45, para facilitar sua remoção do modelo. Após a cristalização do gesso, 
o dente 45 pôde facilmente ser removido e reinserido do modelo, facilitando a confecção dos contatos proximais, bem como a restauração dos términos cervicais (Figura 10).

Figura 10. Troquelização do modelo do gesso. (A) Reposição dos troquéis no molde de silicone. (B) Novo vazamento da moldagem. (C) Aspecto do troquel do dente 45 removido do modelo.

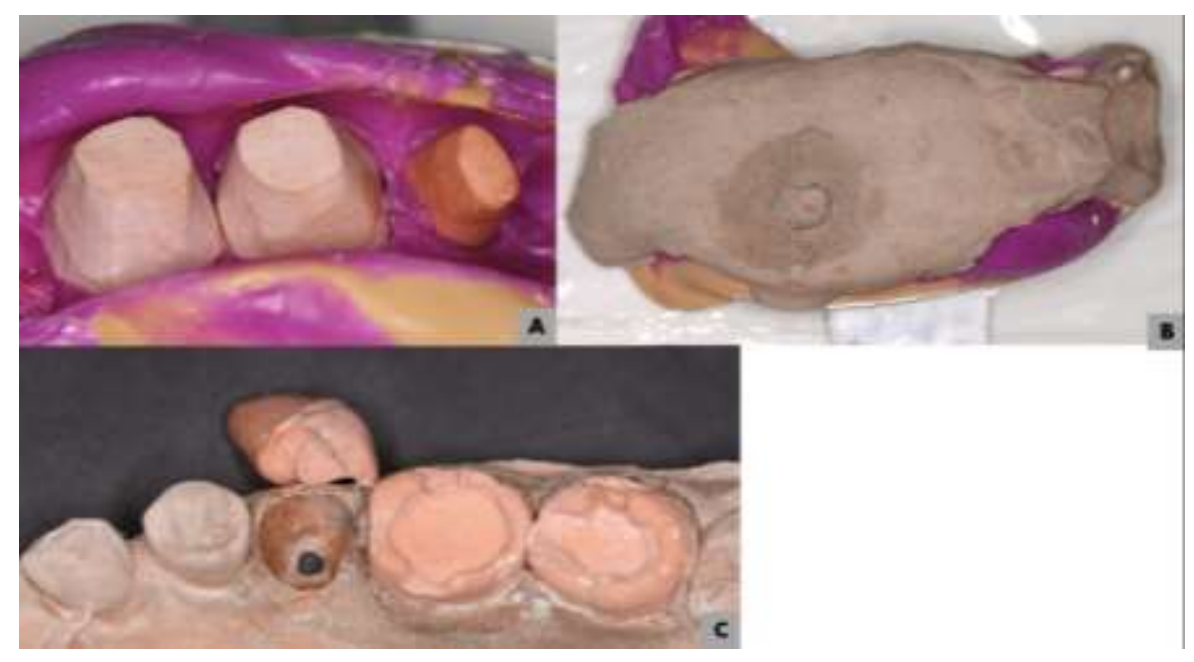

Fonte: Autores.

Após a confecção do troquel, prosseguiu-se com a confecção das restaurações indiretas. Inicialmente, os modelos foram aliviados com cera para escultura (Kota, São Paulo, Brasil) com o objetivo de gerar um alívio para o cimento resinoso (Figura 11). Posteriormente, foi inserido resina composta nanoparticulada (Z350, 3M-ESPE, Minnesota, EUA), com opacidade compatível com a dentina (Figura 12). Na sequência, foi inserido resina composta com translucidez, compatível com o esmalte e finalizado com o uso de pigmentos de cor marrom nos sulcos (Allure, Artcolor, Yller, Rio Grande do Sul, Brasil (Figura 13).

Figura 11. Alívio na superfície interna dos dentes com cera para escultura.

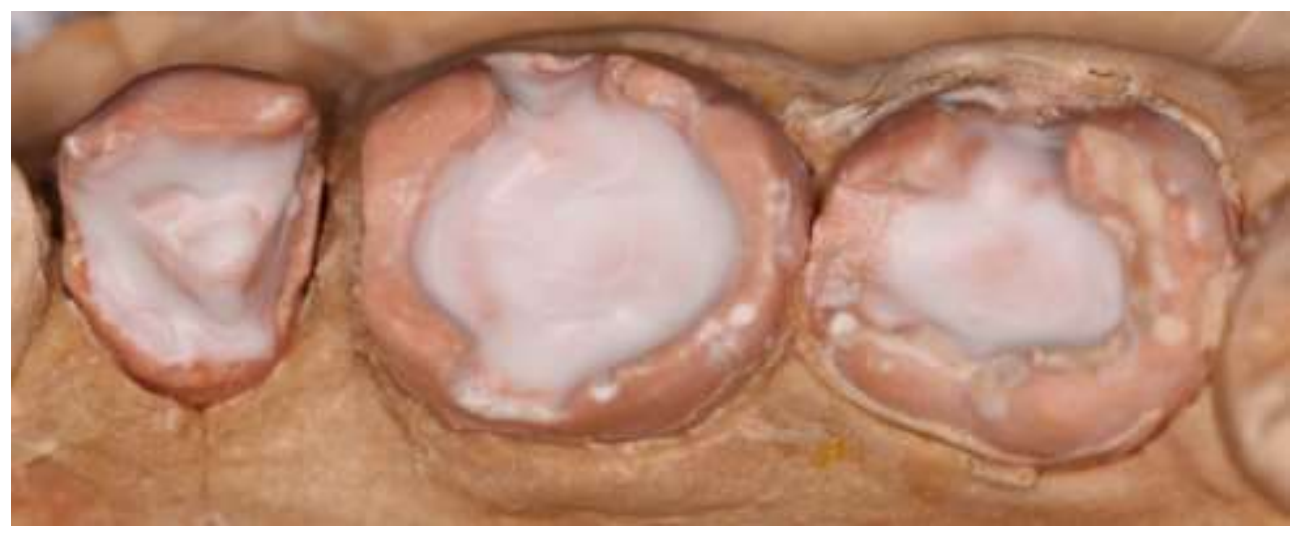

Fonte: Autores. 
Research, Society and Development, v. 10, n. 4, e58810414439, 2021

(CC BY 4.0) | ISSN 2525-3409 | DOI: http://dx.doi.org/10.33448/rsd-v10i4.14439

Figura 12. Inserção da resina composta com opacidade compatível com a dentina.

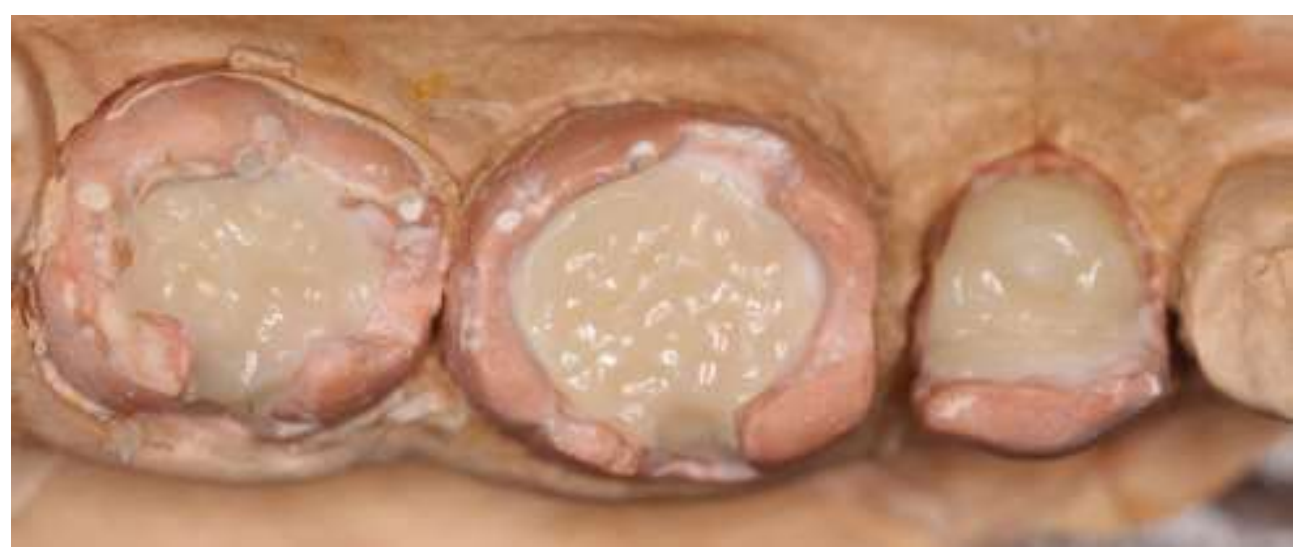

Fonte: Autores.

Figura 13. Inserção da resina composta com translucidez compatível com o esmalte e pigmento marrom nos sulcos.

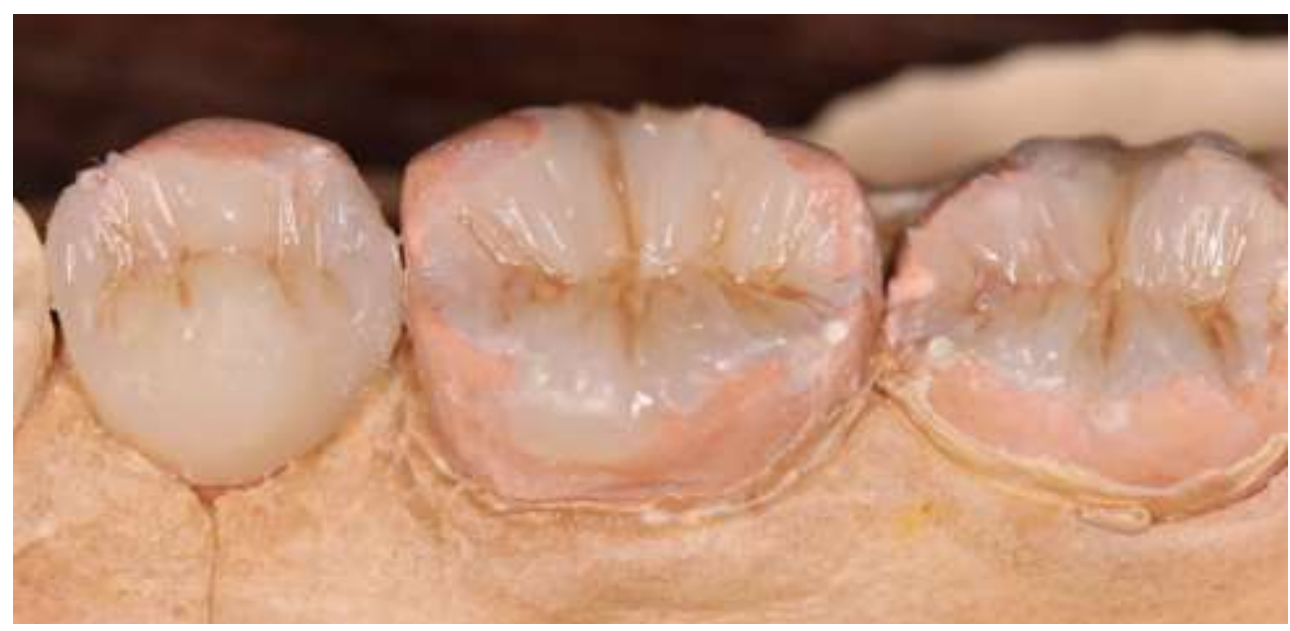

Fonte: Autores.

Após a confecção das restaurações, elas foram removidas do modelo de gesso e inseridas em um recipiente com água, no microondas, na temperatura máxima durante 5 minutos. Este procedimento corresponde à termopolimerização que tem como vantagem converter os monômeros residuais não polimerizados por fotoativação. Em seguida, o procedimento seguiu para a etapa 06 .

\section{Etapa 06: Cimentação das restaurações indiretas.}

$\mathrm{Na}$ sessão seguinte, as restaurações provisórias foram removidas para realização da cimentação. Foi realizado o isolamento absoluto do campo operatório, seguido de profilaxia com pasta de pedra pomes e água e condicionamento do remanescente dental com ácido fosfórico a 37\% (30 segundos em dentina e 15 segundos em esmalte), seguido de sua remoção com spray de água e ar e secagem. As peças restauradoras foram tratadas em sua superfície interna com ácido fosfórico a 37\% por 1 minuto, e após sua remoção, foi aplicado o silano. Por fim, uma camada fina de adesivo universal foi aplicado na peça e polimerização por 20s (Figura 14). 
Research, Society and Development, v. 10, n. 4, e58810414439, 2021

(CC BY 4.0) | ISSN 2525-3409 | DOI: http://dx.doi.org/10.33448/rsd-v10i4.14439

Figura 14. Preparos para cimentação. (A) Isolamento absoluto. (B) Profilaxia com pasta de pedra pomes e água. (C) Condicionamento ácido do dente. (D) Tratamento da face interna da peça com ácido fosfórico. (E) Aplicação do Silano e adesivo.

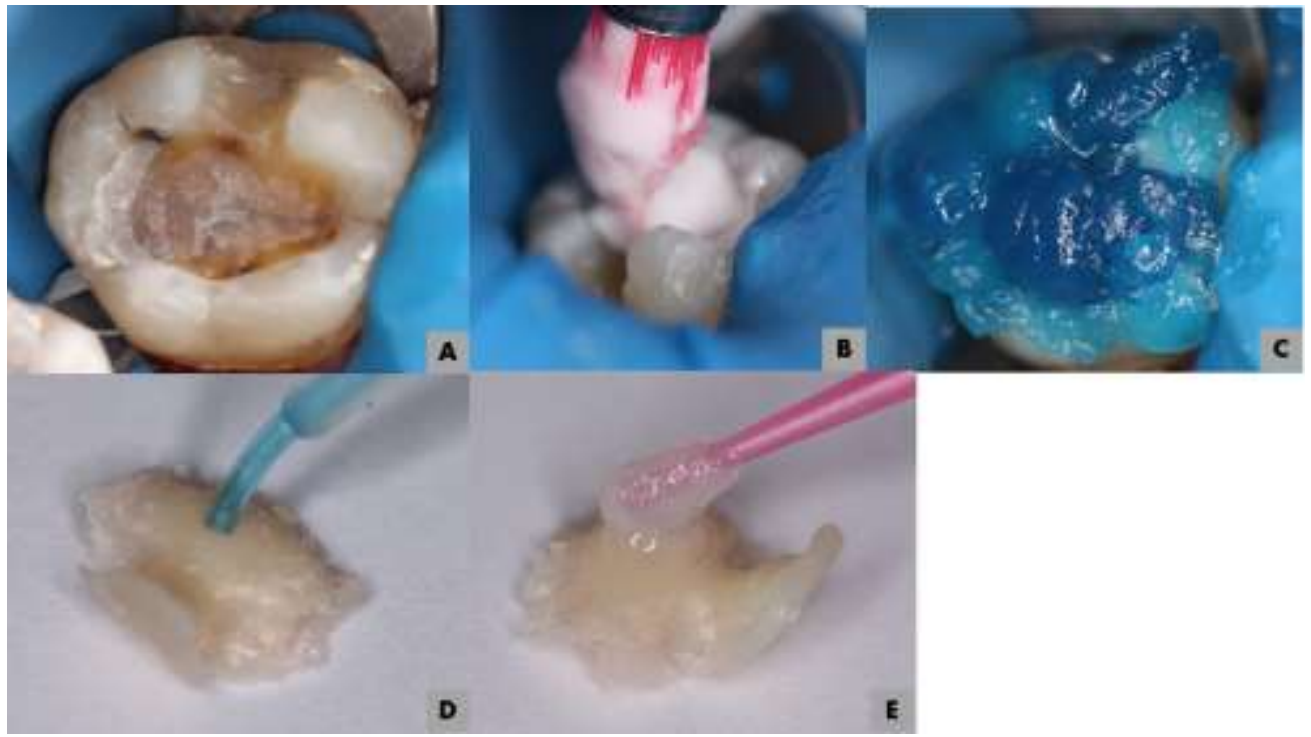

Fonte: Autores.

As peças foram cimentadas com cimento resinoso dual autoadesivo (U200, 3M-ESPE, Minnesota, EUA), através do preenchimento de toda a cavidade com o cimento, inserção da peça sob pressão, remoção dos excessos de cimento com pincel descartável e polimerização por 40 segundos em cada face do dente. $\mathrm{O}$ aspecto clínico após a cimentação de cada dente pode ser consultado na Figura 15.

Figura 15. Aspecto clínico final imediato após as cimentações das restaurações.

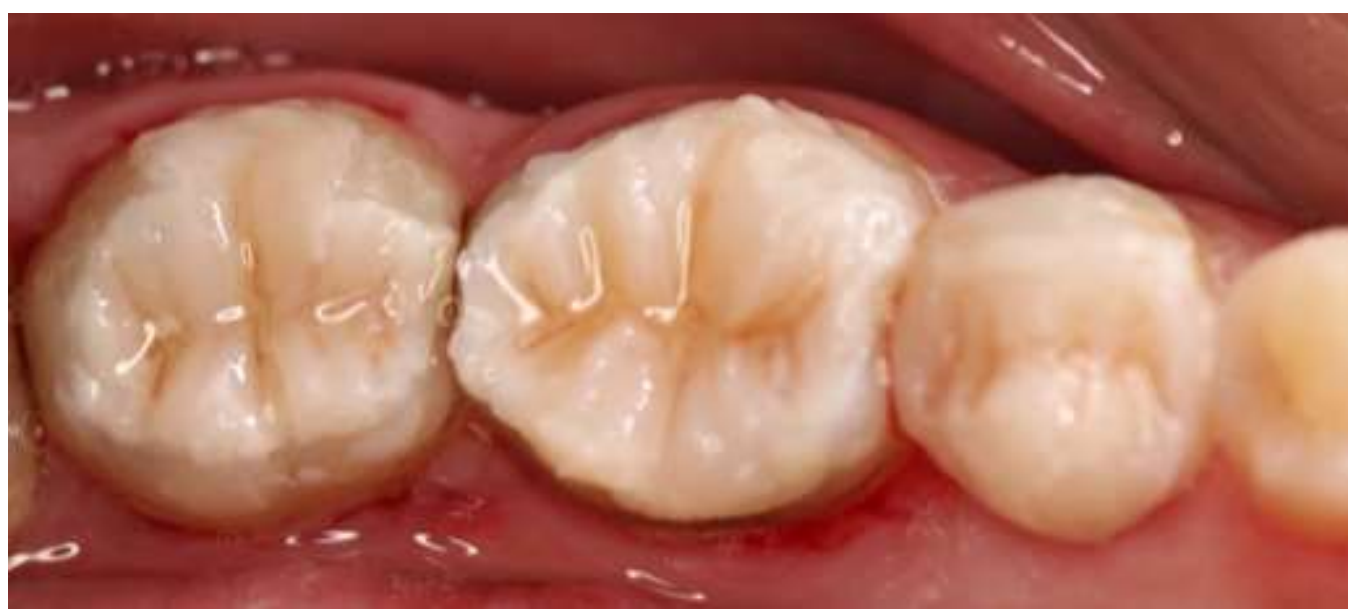

Fonte: Autores.

Após as cimentações, o tratamento seguiu para a etapa 07. 
Research, Society and Development, v. 10, n. 4, e58810414439, 2021

(CC BY 4.0) | ISSN 2525-3409 | DOI: http://dx.doi.org/10.33448/rsd-v10i4.14439

\section{Etapa 07: Ajuste oclusal, acabamento e polimento.}

Após as cimentações, foram realizadas as remoções dos excessos de material restaurador e cimento, com a utilização de pontas diamantadas cônicas, seguido do ajuste oclusal, com auxílio de papel carbono (Figura 16). O polimento das restaurações foi realizado com discos espirais de borracha (Sof-lex espiral, 3M-ESPE, Minnesota, EUA) (Figura 17).

Figura 16. Ajuste oclusal e acabamento. (A) Remoção dos excessos com ponta diamantada cônica. (B) Aspecto clínico após ajuste oclusal e remoção dos excessos.

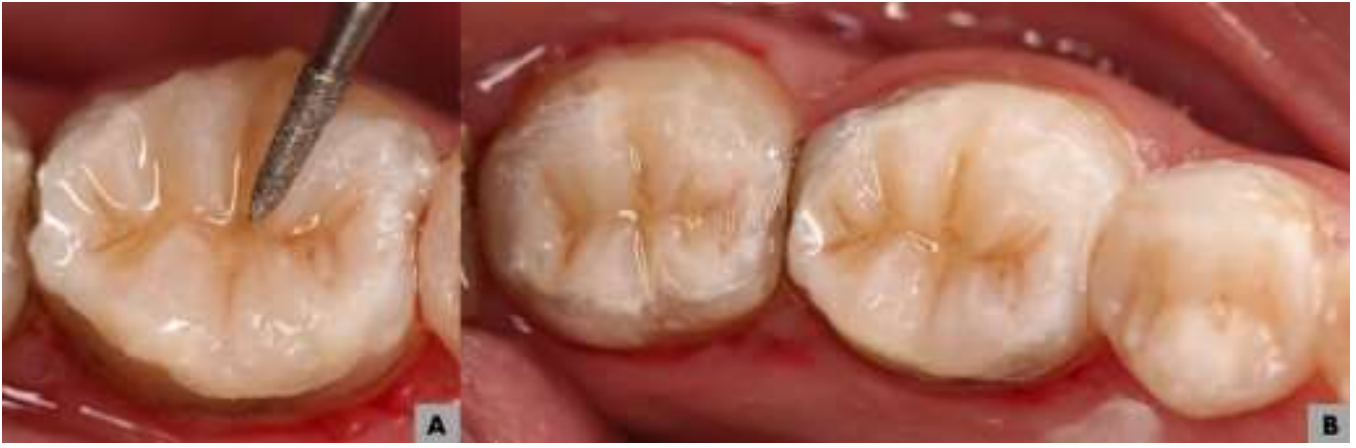

Fonte: Autores.

Figura 17. Polimento das restaurações com discos espirais de borracha Sof-lex espiral.

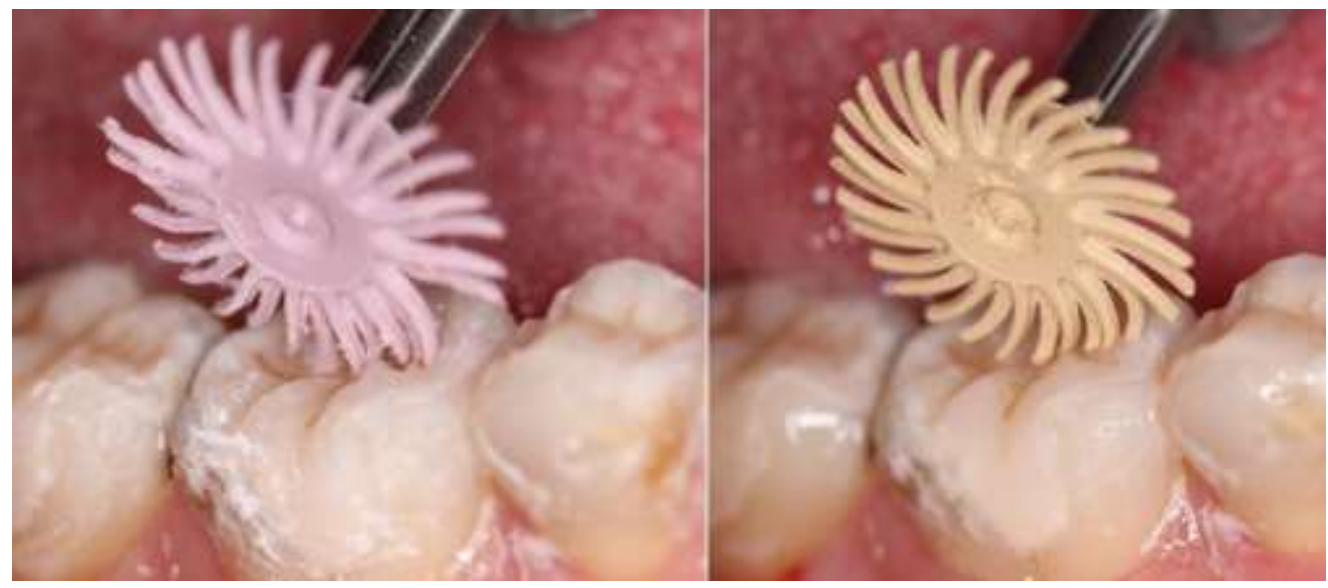

Fonte: Autores.

O aspecto clínico do antes e depois do polimento das restaurações pode ser consultado na Figura 18. 
Figura 18. (A) Aspecto clínico inicial. (B) Aspecto clínico final.

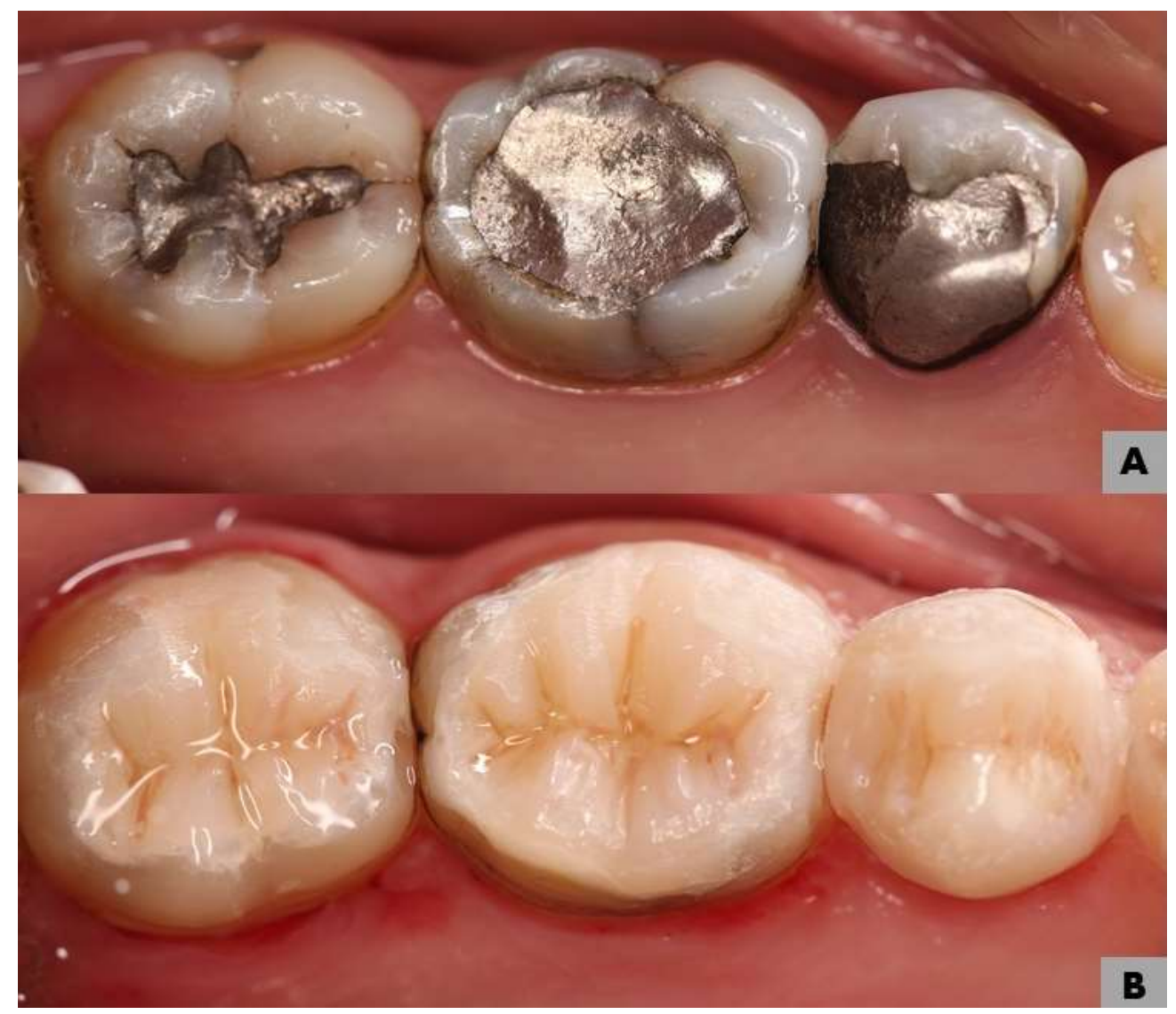

Fonte: Autores.

\section{Resultados e Discussão}

No caso apresentado, optou-se pela confecção de restaurações pela técnica indireta. Essa técnica favorece uma maior conversão polimérica, além de facilitar os contatos proximais e promover um melhor acabamento e polimento das restaurações (Goyatá et al., 2018). Porém, como desvantagem requer um maior número de sessões clínicas (Souto-Maior et al, 2010).

Antes da realização dos preparos cavitários para restaurações indiretas, foi realizado a proteção do complexo dentino pulpar dos dentes nas diferentes profundidades de cavidades. O propósito do tratamento de proteção do complexo dentino pulpar é preservar o máximo de células viáveis capazes de reagir a traumas, fazendo com que os odontoblastos e as novas células odontoblásticas formem dentina reacional (Casarin et al., 2016). Segundo Reis e Loguercio (2007), os materiais protetores do complexo dentino-pulpar devem ter as seguintes características: ser bom isolante térmico e elétrico, ter propriedades bactericidas e/ou bacteriostáticas, apresentar adesão às estruturas dentárias, estimular a recuperação das funções biológicas da polpa, ser insolúvel em meio bucal, favorecer a formação de dentina terciária ou esclerosada, não causar injúrias pulpares, ser biocompatível, apresentar resistência mecânica, inibir a penetração de íons metálicos (escurecimento) e evitar Infiltração bacteriana.

Existem duas formas de proteção do complexo dentino-pulpar: o capeamento pulpar indireto e o capeamento pulpar direto. $\mathrm{O}$ capeamento pulpar indireto pode ser definido como um tratamento conservador, o qual deve ser empregado em cavidades profundas e muito profundas (Casarin et al., 2016). No presente caso, esta terapêutica foi realizada no dente 46 (Figura 04). Este tratamento consiste na remoção da cárie infectada da dentina, a qual não é passível de remineralização, e a camada mais profunda da lesão, próxima à polpa, onde encontra-se a dentina afetada, deve ser preservada (Maltz, Tenuta, Groisman, \& Cury, 2016). A dentina afetada apresenta uma quantidade menor de bactérias e é parcialmente desmineralizada, sendo passível 
de remineralização (Casarin et al., 2016).

Em cavidades profundas (maiores que $0,5 \mathrm{~mm}$ e menores que $1 \mathrm{~mm}$ de distância da polpa), recomenda-se o emprego do cimento de ionômero de vidro como agente de base, usado previamente à confecção das restaurações em resina composta (Reis \& Loguercio, 2007). Esse agente apresenta uma adesão química à dentina, além de apresentar módulo de elasticidade similar à dentina que favorece uma maior dissipação de forças oclusivas (Busato, 2005). O cimento de ionômero de vidro libera flúor, que pode ser um agente importante no processo de remineralização da dentina afetada (Boaventura et al. 2017), além disso esse material é biocompatível e protege a dentina remanescente da ação dos agentes ácidos e dos monômeros resinosos (Reis \& Loguercio, 2007).

Já em cavidades muito profundas (menores que $0,5 \mathrm{~mm}$, em relação à polpa), mas sem exposição pulpar, como apresentada neste caso, antes do emprego do cimento de ionômero de vidro é recomendado o uso do cimento de hidróxido de cálcio, como um agente de forramento (Reis \& Loguercio, 2007). Esse material estimula o espessamento da dentina remanescente, entretanto não apresenta adesão à estrutura dental e, por isso, deve ser sempre protegido por um material de base, como o cimento de ionômero de vidro (Reis \& Loguercio, 2007).

Uma revisão sistemática avaliou se o uso do cimento de hidróxido de cálcio melhora o sucesso clínico do tratamento de lesões de cárie profundas de dentes decíduos e permanentes. Um total de 17 estudos foram incluídos (15 em dentes decíduos e $02 \mathrm{em}$ dentes permanentes). Os resultados evidenciaram que o uso do cimento de hidróxido de cálcio não influenciou o sucesso clínico das restaurações. Entretanto, os autores afirmaram que a evidência do estudo foi de qualidade moderada a muito baixa e sugeriram que mais ensaios clínicos bem planejados, randomizados e controlados fossem realizados para fornecer recomendações mais fortes (Rosa et al., 2019). Portanto, dentro das limitações dos estudos relatados, foi realizado a aplicação do cimento de hidróxido de cálcio na porção mais profunda da cavidade.

Optou-se pelo uso da resina composta, devido sua boa propriedade mecânica e ser uma técnica mais conservadora. A técnica indireta com resina composta pode ainda ser realizada pelo próprio cirurgião-dentista, reduzindo assim os custos com procedimentos laboratoriais. Segundo Azeem e Sureshbabu (2018), a reabilitação com restaurações indiretas corresponde à confecção da peça restauradora fora da cavidade oral, e uma cimentação posterior com cimento resinoso. Apresenta como vantagens menor índice de infiltração marginal e melhor reprodução anatômica das características dentárias, uma vez que são confeccionadas fora da boca. Além disso, a técnica indireta com resina composta apresenta maior resistência mecânica quando comparados as restaurações diretas (Azeem \& Sureshbabu, 2018).

A longevidade das restaurações indiretas depende de um correto preparo da estrutura do remanescente. O preparo da cavidade é definido como desgaste seletivo da estrutura dentária, realizado por meio de pontas diamantadas específicas, objetivando a criação de espaços compatíveis para adaptação da restauração indireta (Veiga et al., 2016). Para minimizar o desgaste de estruturas já fragilizadas, a conformação expulsiva com resina composta como aplicada no presente caso, pode ser empregada. Veiga et al. (2016) ilustra a importância dos princípios do preparo para favorecer uma maior longevidade clínica, devendo-se evitar áreas de concentração interna e estresse, respeitar a espessura que o material deve apresentar e criar um eixo de inserção passiva da peça. Os preparos cavitários foram moldados com silicone de adição e vazados com gesso tipo IV. O silicone de adição apresenta uma boa estabilidade dimensional, porém demonstra uma natureza hidrofóbica, devendo ser utilizada em condição seca para menor alteração dimensional (Silva et al., 2016). Além disso, devido à alta estabilidade dimensional, as moldagens com este material podem ser vazadas mais de uma vez (Soganci et al., 2018). Essa característica permitiu a realização da técnica de troquelização, empregada neste estudo, por meio de duplo vazamento.

A cimentação foi realizada com cimento resinoso dual, devido à espessura da peça restauradora. Durante a cimentação de restaurações indiretas, alguns fatores podem influenciar na polimerização do cimento, como a espessura e opacidade das restaurações. Para tanto, nestas situações, é importante utilizar um material que possua uma presa iniciada por fotoativação e 
finalize sua polimerização de forma química (Fonseca et al., 2015).

No caso apresentado o polimento da restauração se deu com os espirais borrachóides Sof-lex espiral (3M-Espe). Sabese que as resinas compostas apresentam sorção à água e concedem a integração de pigmentos da dieta em sua matriz. Para tanto, associando ainda o uso de um adequado material restaurador, ele deve exibir excelente acabamento e polimento, pois quando realizado adequadamente, minimiza as porosidades e consequentemente, dificultam a variação de cor destes materiais (Almeida et al., 2019).

\section{Conclusão}

No caso apresentado, as restaurações indiretas favoreceram uma boa estética, uma vez que foram confeccionadas fora da cavidade bucal, teve a etapa de escultura facilitada e permitiu bons níveis de adaptação dental.

\section{Referências}

Almeida, L., Santin, D. C., Maran, B. M., Naufel, F. S., \& Schmitt, V. L. (2019). Avaliação do manchamento e da rugosidade superficial de materiais restauradores diretos após diferentes sistemas de polimento: Estudo in vitro. Revista de Odontologia da UNESP, 48(1), 1-10.

Angeletaki, F., Gkogkos, A., Papazoglou, E., \& Kloukos, D. (2016). Restaurações compostas inlay/onlay diretas versus indiretas em dentes posteriores: Uma revisão sistemática e meta-análise. Journal of Dentistry, 53(7), 12-21.

Azeem, R. A., \& Sureshbabu N. M. (2018). Clinical performance of direct versus indirect composite restorations in posterior teeth: A systematic review. Journal of Conservative Dentistry, 21(1), 2-9.

Boaventura, J. M. C., Roberto, A. R., de Oliveira Becci, A. C., Ribeiro, B. C. I., de Oliveira, M. R. B., \& de Andrade, M. F. (2017). Importância da biocompatibilidade de novos materiais: revisão para o cimento de ionômero de vidro. Revista de Odontologia da Universidade Cidade de São Paulo, 24(1), 4250 .

Busato, A. L. S. Dentística: filosofia, conceitos e prática clínica. Dentística: filosofia, conceitos e prática clínica - Grupo Brasileiro de Professores de Dentística. Revodonto, p. 95-124, 2005.

Cardoso, Renan M., Cardoso, Randerson M., Gomes, M. P., Guimarães, R. P., Menezes Filho, P. F., \& Silva, C. H. V. (2012). Onlay com resina composta direta: Relato de caso Clínico. Odontologia Clínico-Científica, 11(3), 259-264.

Casarin, D., Calza, J. V., Silva, S. B. A., \& Silva, V. A. (2016). Uso da proteção do complexo dentino-pulpar por discentes de odontologia. Journal of Oral Investigations, 5(1), 40-49.

Costa, C. A. Z., Leite, M. L. A. S., Duarte, R. M., Andrade, A. K. M., \& Soares, D. G. (2018). Bond strength and cytotoxicity of a universal adhesive according to the hybridization strategies to dentin. Brazilian Dental Journal, 29(1), 68-75.

Costa, C. A. Z., Hebling, J., Scheffel, D. L. S., Soares, G. D. S., Basso, F. G., \& Ribeiro, A. P. D. (2014). Methods to evaluate and strategies to improve the biocompatibility of dental materials and operative techniques. Dent Mater, 30, 769-784.

Dias, G. F., Ferraz, T. R. K., Salanti, L., Mello, A., \& Alves, F. B. T. (2017). Restaurações indiretas em resina composta: uma alternativa clínica para molares decíduos. Revista Stricto Sensu, 2(2).

Espíndola-Castro, L. F., Guimarães, R. P., Souza, F. B., Monteiro, G. Q. M., Filho, P. F. M., Fernandes, L. O., \& Silva, C. H. V. (2019). A 14-year follow-up of resin composite occlusal restorations: Split mouth randomised clinical trial and wear evaluation by optical coherence tomography. Journal of Clinical \& Diagnostic Research, 13(1), 10-15.

Fonseca, G. S., Correia, A. M. O., Griza, S., Vilarroel, M., Takeshita, W. M., \& Mendonça, A. A. M. (2015). Efeito da intensidade de fontes de luz e barreiras de cerâmica na microdureza de cimento resinoso dual. Revista odontológica UNESP, 44(4), 207-212.

Goyatá, F. R., Siqueira, V. V., Novaes, I. C., Arruda, J. A. A., Barreiros, I. D., Novaes Júnior, J. B., Lanza, C. R. M., \& Moreno, A. (2018). Técnicas alternativas de restauração indireta em resina composta: Relato de casos clínicos. Archives Of Health Investigation, 7(7), 274-280

Guimarães, A. A. A., Cunha, J. A. S. C., Magalhães, L. R., Neves, D. E. R., Monteiro, G. Q. M., \& Espíndola-Castro, L. F. (2020). Substituição de restaurações em amálgama de prata por resina composta pelas técnicas direta e indireta: caso clínico. Rev Ciência Saúde, 5(1), 14-19.

Hansrani, V. K., Laverty, D., \& Brunton, P. (2019). The use of indirect resin composite restorations in the management of localized anterior tooth wear: a clinical update. Dental Update, 46(9), 812-816.

Huth, K. C., Chen, H. Y., Mehl, A., Hickel, R., \& Manhart, J. (2011). Clinical study of indirect composite resin inlays in posterior stressbearing cavities placed by dental students: results after 4 years. J. Dent., 39(7), 478-488.

Maltz, M., Tenuta, L. M. A., Groisman, S., \& Cury, J. A. (2016). Cariologia: Conceitos Básicos, Diagnóstico e Tratamento Não Restaurador: Série Abeno: Odontologia Essencial-Parte Clínica. Artes Médicas. 
Research, Society and Development, v. 10, n. 4, e58810414439, 2021 (CC BY 4.0) | ISSN 2525-3409 | DOI: http://dx.doi.org/10.33448/rsd-v10i4.14439

Martins, L. M, Lorenzoni, F. C, Farias, B. C, Lopes, L. D. S, Bonfante, G, \& Rubo, J. H. (2010). Comportamento biomecânico das cerâmicas odontológicas: Revisão. Cerâmica, 56(338), 148-155.

Melo, A. R. S., Almeida, A. N. C. L., Sales, T. L. L., Madureira, I. T., Figueroa, A., \& Leite, E. B. C. (2015). Reconstrução de dentes severamente destruídos com pino de fibra de vidro. Odontologia Clínico-Científica, 14(3), 725-728.

Monteiro, R. V., Taguchi, C. M. C., Monteiro Junior, S., \& Bernardon, J. K. (2017). Técnica semidireta: Abordagem prática e eficaz para restauração em dentes posteriores. Revista Ciência Plural, 3(1), 12-21.

Mori, M., Ueti, M., Matson, E. \& Saito, T. (1997). Estudo da distribuição das tensões internas, sob carga axial, em dente hígido e em dente restaurado com coroa metalocerâmica e retentor intra-radicular fundido: Método do elemento finito. Revista Odontológica da Universidade de São Paulo, 11 (2), 99-107.

Poimenova, A., Kitraki, E., Kakaboura, A., \& Rahiotis, C. (2018). Early responses of human pulp to direct capping with resin adhesive systems and calcium hydroxide. Dental Materials, 34(4), e73-e82.

Pessoa, V. L. R., Monteiro, G. Q. M., Oliveira, N. G., \& Espíndola-Castro, L. F. (2019). Desgaste dentinário seletivo associado a pino de fibra de vidro. Revista Ciência Plural, 5(3), 132-142.

Ramírez, L. M. P., Méndez, M. R., Cornejo, P. M. A., Llamas, O. F. J., \& Escalante, B. S. A. (2016). Resistencia a la fractura in vitro de incrustaciones cerámicas usando dos materiales como bases cavitarias. Revista ADM, 73(3), 139-143.

Reis, A., \& Loguercio, A. D. (2007). Materiais dentários restauradores diretos. Santos, São Paulo, 578

Rosa, W. L. O., Lima, V. P., Moraes, R. R., Piva, E., \& Da Silva, A. F. (2019). Is a calcium hydroxide liner necessary in the treatment of deep caries lesions? A systematic review and meta-analysis. International endodontic journal, 52(5), 588-603.

Silva, F. C. F. A., Souza, L. C., Rodrigues, N. S., Cunha, D. A., Apolonio, F. M., \& Saboia, V. P. A. (2016). Técnica de moldagem modificada usando silicona de adição. Rev. Assoc. Paul. Cir. Dent., 70(4), 364-368.

Soganci, G., Cinar, D., Caglar, A., \& Yagiz, A. (2018). 3D evaluation of the effect of disinfectants on dimensional accuracy and stability of two elastomeric impression materials. Dental Materials Journal, 37(4), 675-684.

Souto Maior, J. R., Lima, A. C. S., Souza, F. B., Silva, C. H. V., Menezes Filho, P. F., \& Beatrice, L. C. S. (2010). Aplicação clínica de cimento resinoso autocondicionante em restauração inlay. Odontologia Clínico-Científica, 9(1), 77-81.

Stape, T. H. S., Bertaglia, P. C., Santos-Caldeira, M. M. P., \& Martins, L. R. M. (2013). Coroa endodôntica adesiva: Tratamento estético e funcional alternativo para molares com extensa destruição coronária e espaço interoclusal reduzido. Revista Dental Press de Estética, 10(3), 94-105.

Veiga, A. M. A., Cunha, A. C., Ferreira, D. M. T. P., Fidalgo, T. K. S., Chianca, T. K., Reis, K. R., \& Maia, L. C. (2016). Longevity of direct and indirect resin composite restorations in permanent posterior teeth: A systematic review and meta-analysis. Journal of Dentistry, 54(1), 1-12. 